\title{
Cellular Automata Ship Traffic Flow Model Considering Integrated Bridge System
}

\author{
Hongxiang Feng \\ Marine Merchant College, Shanghai Maritime University \\ 1550 Haigang Ave, Shanghai, P.R.China, 201306 \\ yiyouyishi@163.com
}

\begin{abstract}
For the purpose of efficiency and safety in marine traffic, and considering that ships have to change lane to move on in case of waterway partial closure caused by a marine work zone or an accidence, a new NaSch ship traffic model considering Integrated Bridge System (IBS) is presented, and then a cellular automata model considering IBS for partial reduction waterway is proposed. By numerical simulation, fundamental diagram and time-space spot diagrams of ship traffic flow and that when accidence happens and recovers are given. At last, a numerical example is forwarded to analyze the effect to waterway transit capacity by precautionary area length and ship arrival rate. The model may be applied in decisionmaking simulation and increase the transit capacity of waterway.
\end{abstract}

Keywords: Cellular automata, Ship traffic flow, Traffic simulation, Marine work zone, Lane closure, integrated bridge system

\section{Introduction}

For the virtues of discretization in space, time and state, and easy implementation in algorithm on a computer, cellular automata (CA) [1] model has been widely developed and used in traffic flow study [2-9]. At present, CA research in transportation mainly concentrates in road traffic; research and application to marine traffic are relatively less and in the ascendant [9].

Combining CA with Agent, literature [7] carried preliminary research on ship traffic flow, the model can increase computational efficiency but it's lack of dynamical model; According to Wolfram Rule 184, literature [8] had an attempt to construct ship traffic flow CA model, however its model fails to embody the characteristics of acceleration, deceleration and randomization, and could not reflect the various type and size of ship. Literature [9] used CA model and carried out an application research to ship traffic flow in Malacca strait, but the model is difficult to apply in another case.

All the mentioned attempts of CA in marine traffic are preliminary. As described in literature [7] and [9], there are several difficulties for CA application in marine traffic comparing with road traffic: 1) Different from the standard vehicles, ships vary greatly in type and size; 2) Because of the broad navigatable waters, ships could navigate with relative freedom; 3) Marine traffic control and navigational facilities are relatively simple and rare, however navigational rules are complex and highly technical; 4) Update rules in road traffic cannot be simply applied to ship traffic flow. Therefore, CA ship model should be established as per appropriate marine characteristics. 


\section{Model}

\subsection{Characteristics of Ship Traffic Flow}

Compared with road traffic, characteristics of marine traffic list as below:

(1) According to the requirement of Paragraph 2.4 of SOLAS (International Convention for the Safety of Life at Sea, 1974) Regulation V-19, all ships of 300 gross tonnage and upwards engaged on international voyages and cargo ships of 500 gross tonnage and upwards not engaged on international voyages and passenger ships irrespective of size shall be filled with an automatic identification system (AIS). AIS shall:

.1 provide automatically to appropriately equipped shore stations, other ships and aircraft information, including the ship's identity, type, position, course, speed, navigational status and other safety-related information;

.2 receive automatically such information from similarly fitted ships.

(2) According to the requirement of Paragraph 2.3 of SOLAS Regulation V-19, all ships of 300 gross tonnage and upwards and passenger ships irrespective of size shall be filled with a $9 \mathrm{GHz}$ radar, or other means to determine and display the range and bearing of radar transponders and of other surface craft, obstructions, buoys, shorelines and navigational marks to assist in navigation and in collision avoidance.

(3) According to the requirement of SOLAS Regulation IV-7, each ship shall be provided with a VHF (Very High Frequency) radio installation capable of transmitting and receiving.

(4) When navigating in VTS (Vessel Traffic Services) coverage, a ship can obtain safety-related information from VTS center and its actions are always in the systemic monitoring and supervision of VTS.

(5) Different from that a car is always driven by an individual driver, a ship is commanded by a team which consists of captain, duty officer, pilot and watch keepers when navigates in waterway.

As mentioned above, by the advantage of Integrated Bridge System, a ship can grasp the real-time motion of other ships in any time, and then makes his decision to handle ship. As a result opposite to road traffic, reaction of divers, ship behaviors, ship gap and collision avoidance action are all changed.

\subsection{Hypothesis}

In order to introduce CA model into ship traffic field, hypothesis are given as below:

1) All ships are ideal, and standardization processing is carried out to the various ship lengths; after the standardization, ship lengths follow discrete distribution with a certain statistical regularity and the distribution law is obtained by observation of ship traffic flow.

2) Each waterway allows only one ship pass through by one-way, so we can just take the ship length into consideration and ignore the effect of ship width.

3 ) The waterway is ideal, and ships are not affected by waterway draft, wind, wave, current, shallow water effect and bank effect; Waterway is treated to be straight forward, and always remains unchanged, which is equal to that ships never slow down in the process of altering course. 
4) For macro consideration, maneuver characteristics such as kick is ignored when ships change lane, if the requirements of lane changing met, ships directly update to the next position of neighbor waterway.

5) Considering that the amendment of SOLAS had come into effect on July 1, 2002, all ships are regarded to equip with AIS already.

6) Open boundary condition is adopted, ships generate with a certain distribution and quit when reach at the end of waterway. Generation rules of ships are obtained by observation of ship traffic flow.

\subsection{NaSch Ship Traffic Flow Model Considering IBS}

Combining with the characteristics of ship traffic flow and above hypothesis, we assume that $\operatorname{ships}(X, L, V)$ distribute randomly along the one-dimensional discrete cell chain of length $n$, which has three properties cells, length and velocity. By IBS, each ship can receive necessary collision avoidance information such as distance, position, speed, length, CPA (Closest Point of Approaching) and ship name from other ships at time $t$. Based on these information, ship can accurately infer distance, position, speed, and relative position as well as whether to constitute a collision risk with those ships at time $t+1$, and then decide its actions at time $t$.

In the cell chain, each cell may either be occupied by one ship or be empty, that's $X_{i}(t) \in\{0,1\}$. Each ship occupies $L_{i}(t)$ cells which are adjacent, $L_{i}(t) \in\left\{1, \ldots, L_{\max }\right\}$. $V_{i}(t)$ is the velocity of ship $i$ at time $t$, and $V_{i}(t) \in\left\{0,1, \ldots, V_{\max }\right\} \cdot d_{i}(t)$ is distance to the nearest front ship, and

$$
d_{\mathrm{i}}(t)=\left\{\begin{array}{cc}
X_{\mathrm{f}}(t)-X_{\mathrm{i}}(t)-L_{\mathrm{i}}(t) & \text { with_ship_in_front } \\
n-X_{\mathrm{i}}(t) & \text { without_ship_in_front }
\end{array}\right.
$$

Under the open boundary conditions, ships move from west to east and in each discrete time step $t \rightarrow t+1$ update their status according to the following rules in parallel and synchronously:

1) Acceleration

$$
V_{\mathrm{i}}(t)=\min \left(V_{\mathrm{i}}(t)+1, V_{\max }\right)
$$

2) Slowing down(due to other ships)

$$
V_{\mathrm{i}}(t)=\min \left(V_{\mathrm{i}}(t), d_{\mathrm{i}}(t)+L_{\mathrm{i}}(t)-d_{\text {safe }}\right)
$$

3) Randomization

$$
V_{\mathrm{i}}(t)=\max \left(V_{\mathrm{i}}(t)-1,0\right)
$$

4) Position and velocity update

$$
\begin{array}{cc}
L_{\mathrm{i}}(t+1) & =0 \\
\text { Original size, position and velocity: } & X_{\mathrm{i}:\left(i+L_{\mathrm{i}}(\mathrm{t})-1\right)}(t+1)=0 \\
V_{\mathrm{i}}(t+1) & =0
\end{array}
$$




$$
\text { New size, position and velocity: } \begin{gathered}
L_{i+V_{i}(t)}(t+1)=L_{i}(t) \\
X_{\left(i+V_{i}(t)\right):\left(i+V_{i}(t)+L_{i}(t)-1\right)}(t+1)=1 \\
V_{i+v_{i}(t)}(t+1)=V_{i}(t)
\end{gathered}
$$

In particular, when $L_{\mathrm{i}}(t)=1$ and without the safety-related information such as position, speed and so on from other ships, this model degradates into the classic NaSch model.

Acceleration rules reflect that ship officer/captain/pilot is pursuing the speed with maximum limit; deceleration rule is to keep a safety distance from fore ship; slowdownrandom rule is to characterize officer/captain/pilot in technical level, waterway environment and ship performance etc., (the higher officer/captain/pilot in technical level, the better waterway environment and the better ship performance, then the smaller random deceleration probability $p$ ).

\subsection{CA Model for Partial Reduction Waterway considering IBS}

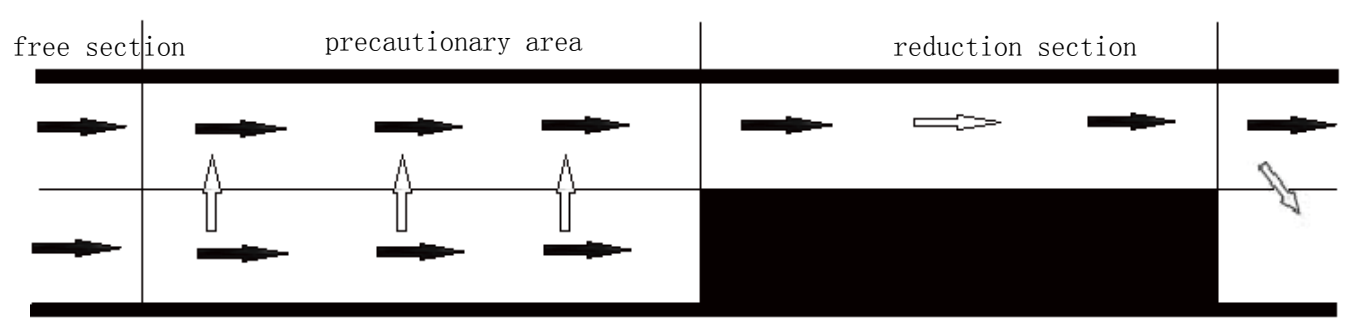

Figure 1. Schematic Diagram of Partial Reduction Waterway

NaSch ship traffic flow model is suitable for single-lane waterway. For partial reduction waterway with dual-lane, ships have to change lanes, and lane change rules should add to control the lane-change behavior. Rules are below:

A) Outside precautionary area, each lane is treated as an independent waterway; ships update in parallel in their own lane as per ship NaSch rules;

B) In precautionary area, ships slowdown, and maximum speed limit decreases from $v_{-}$max to $\mathrm{v}_{\mathrm{p}_{\_} \max }$; only ships at right lane are allowed to change lane to left lane in parallel as per lane change rule;

C) Partial reduction sector is waterway with a single lane, and ships shall navigate with safety speed.

Lane change rules are:

$$
\begin{gathered}
d_{\text {safe1 }}>d_{\mathrm{i}}(t+1) \\
d_{\text {safe2 }}<d_{\mathrm{i}, \text { other }}(t+1) \\
d_{\text {safe3 }}<d_{\mathrm{i}, \text { back }}(t+1)
\end{gathered}
$$

Where $d_{\mathrm{i}, \text { other }}(t+1)$ and $d_{\mathrm{i}, \text { ack }}(t+1)$ are respectively distances between ship $i$ and fore and aft ships thereof at the neighbor lane at time $t+1, d_{\text {safe }_{1}}, d_{\text {safe2 }}$ and $d_{\text {safe3 } 3}$ are safe distances between own ship and fore ship, fore ship and aft ship at neighbor lane.

Rule 1 is the motivation to lane change, that's in the own lane there is no enough space in front for the ship $i$ to sail with its expecting speed; Rules 2 is the sailing condition of neighbor lane, that's for the ship $i$ it's better to sail at neighbor lane than at its own lane; Rules 3 is 
safety conditions, that's the lane change behavior of ship $i$ would not cause traffic jam at neighbor lane.

\section{Algorithm and Simulation}

Above-mentioned NaSch ship traffic flow model considering IBS and CA model for partial reduction waterway considering IBS can be described by algorithms in Figures 2- 3. Through the development of visual software, simulation of ship traffic flow is more intuitive, and easier to analysis. The time-space spot diagrams could vividly reproduce the movement characteristics of ship traffic flow.

Figure 4 is time-space spot diagram for NaSch ship traffic flow model considering IBS (waterway length $=1500$, original state: 30 ships along waterway, ship arrival rate $=4, p=$ 0.25 ) and Figure 8 is that as accidence happens and recovers (waterway length $=1500$, original state: 30 ships along waterway, ship arrival rate $=4, p=0.25$. When $t=300$ and $X=$ 1200, a ship accidence happened, and the accidence last for 500). In Figure 5, ships update their position as time went on, and the space trajectories looked like flowing fluid. In Figure 5 , when accidence happened density wave spread upstream gradually; and when accidence recovered traffic jams scattered and disappeared rapidly.

Figure 6 and Figure 7 are fundamental diagrams of NaSch ship traffic flow model considering IBS (waterway length $=1500$, original state: 30 ships along waterway, ship arrival rate $=4, p=0.25$. When $t=300$ and $X=1200$, a ship accidence happened, and the accidence last for 500).

Figure 8 and Figure 9 are for CA model for partial reduction waterway considering IBS.

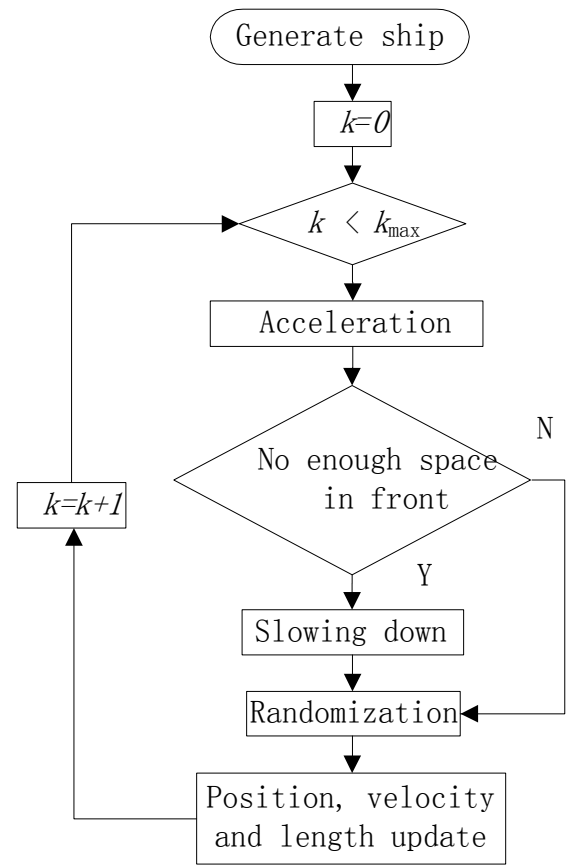

Figure 2. NaSch Ship Traffic Flow
Model considering IBS

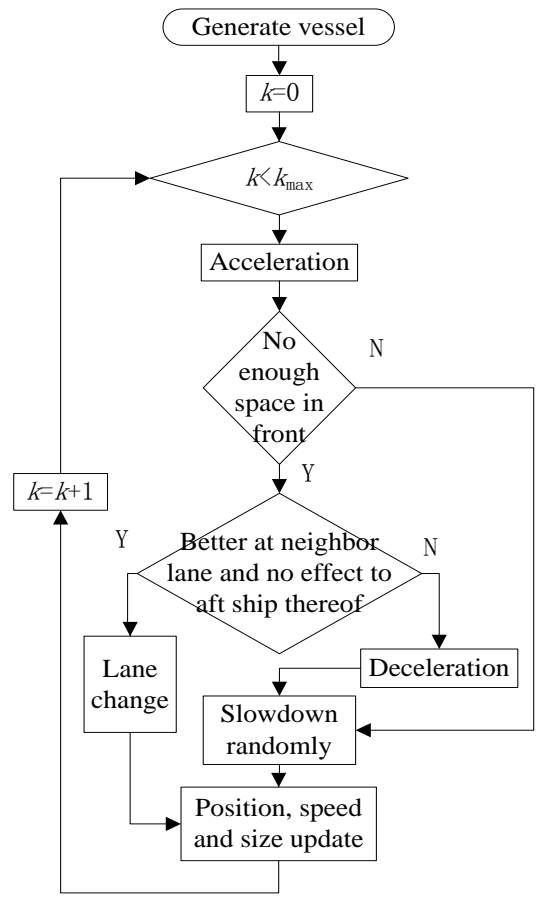

Figure 3. CA Model for Partial Reduction Waterway considering IBS 


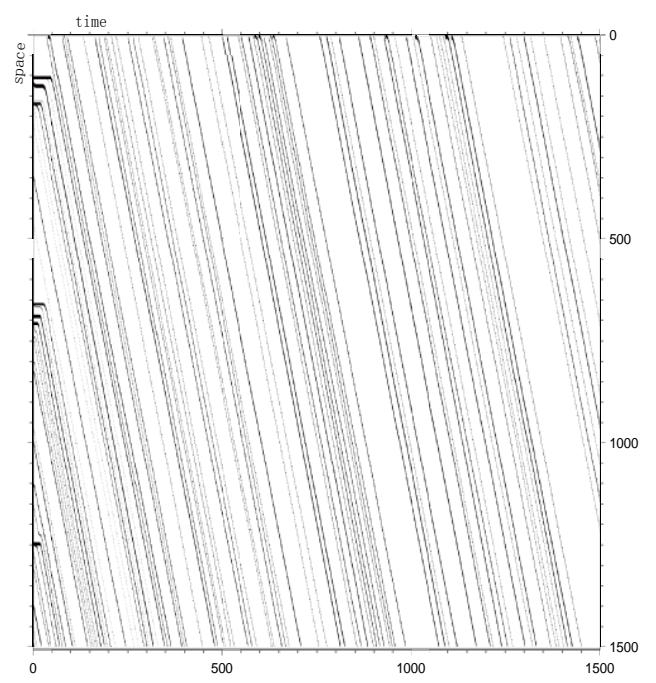

Figure 4. Time-space Spot Diagram for NaSch Ship Traffic Flow Model considering IBS

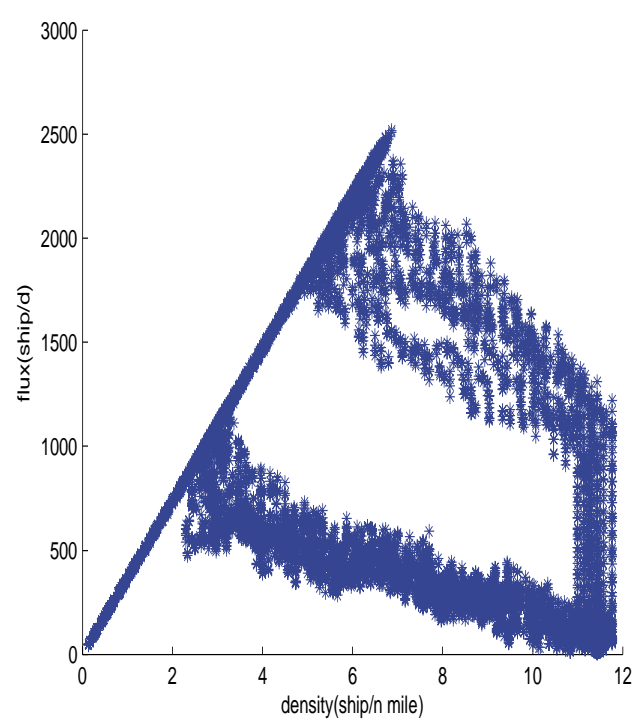

Figure 6. Density and Flux as a Function

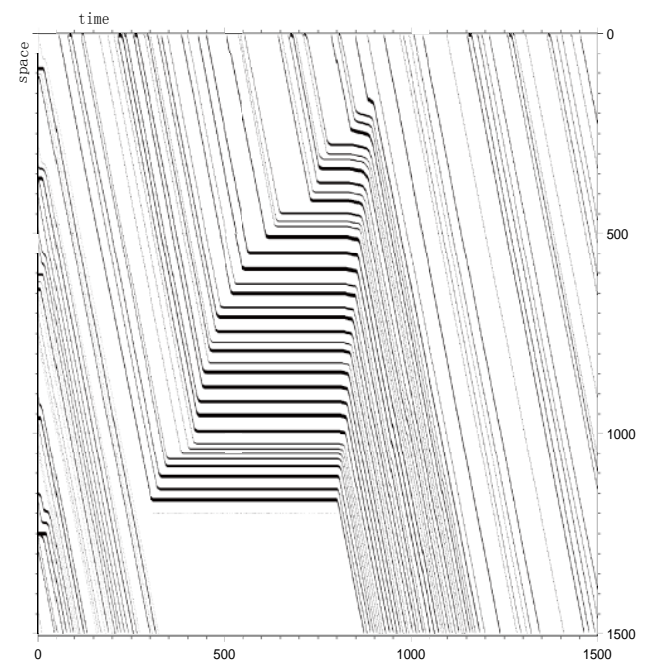

Figure 5. Time-space Spot Diagram for NaSch Ship Traffic Flow Model considering IBS as Accidence Happens and Recovers

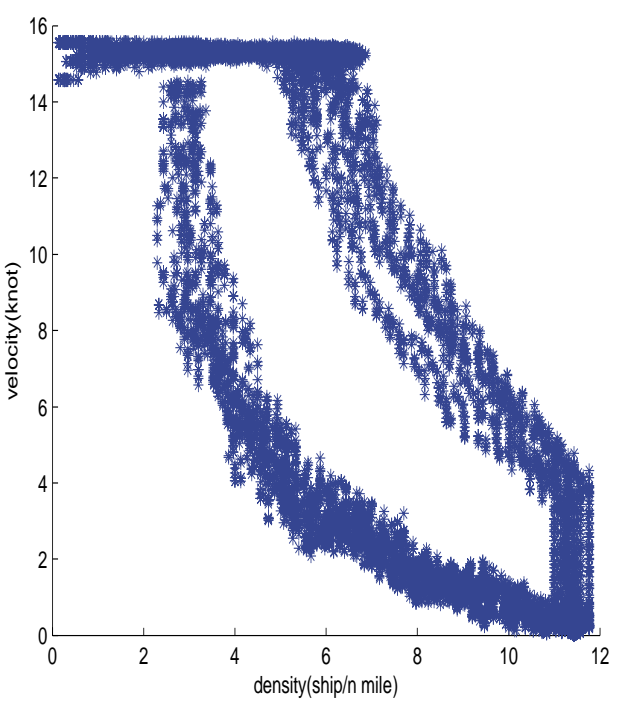

Figure 7. Density and Velocity as a Function 
navigatible lane

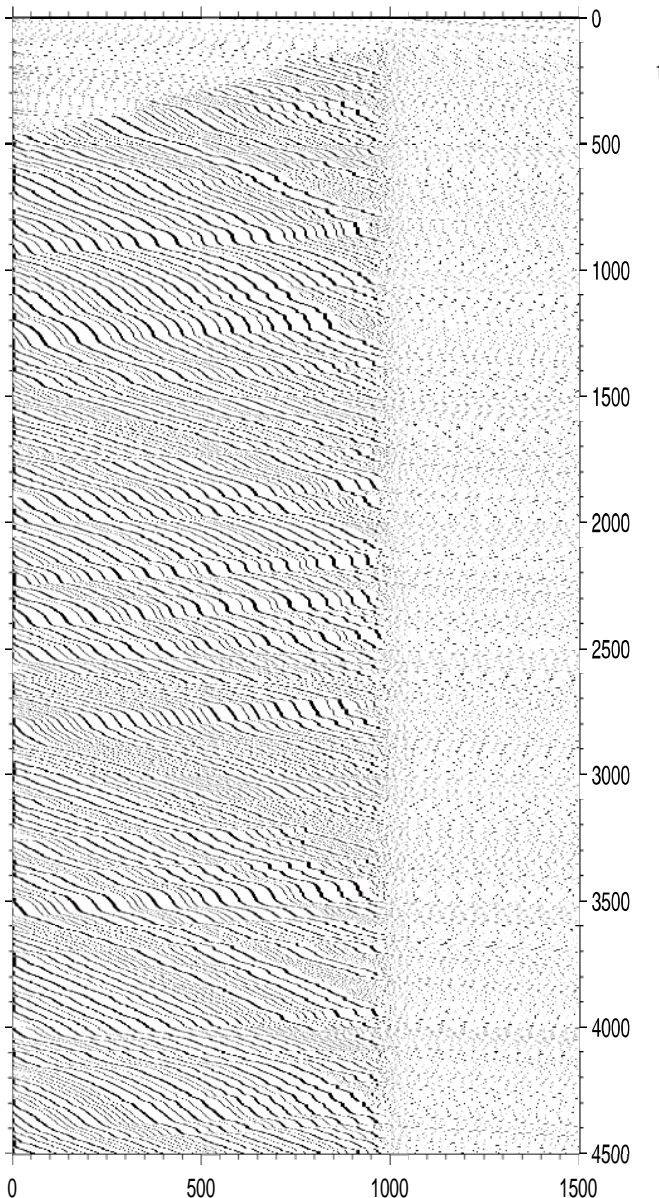

Figure 8. Time-space Spot Diagram for Navigable Waterway

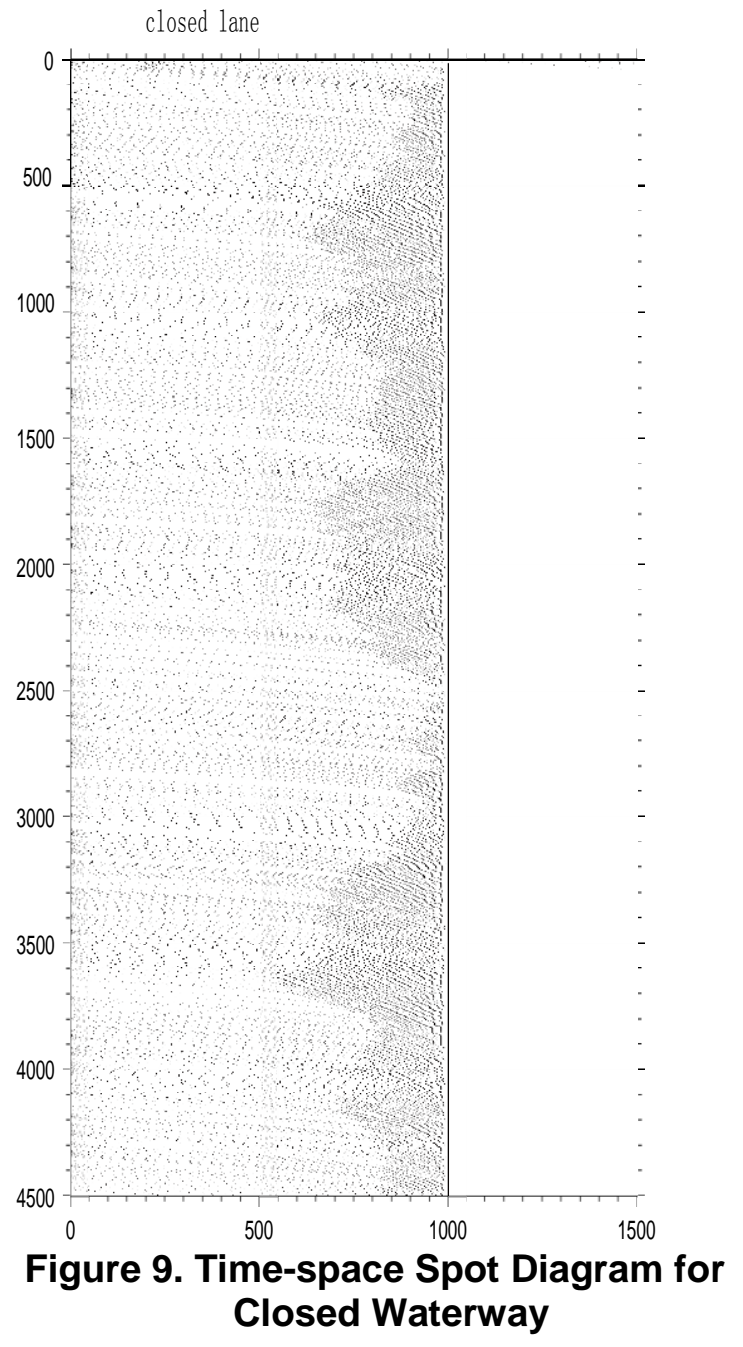

\section{Example}

Assume that a waterway exists, and its unilateral waterway consists of main waterway $(\mathrm{M} / \mathrm{W})$ and auxiliary waterway $(\mathrm{A} / \mathrm{W})$. The waterway is $30 \mathrm{n}$ miles in length, $\mathrm{M} / \mathrm{W}$ thereof designed for large ships and $\mathrm{A} / \mathrm{W}$ for small ships. For large ships, $L \in[90,300](\mathrm{m})$, $V \in[10,16]$ ( knot); and for small ships $L \in[30,120](m), V \in[2,12]$ ( knot). Speed limit is $10 \mathrm{knot}$ in precautionary area. In each waterway ships shall not overtake or sail side by side.

In normal circumstances, large ships and small ships sail in M/W and A/W separately, and small ship shall not enter M/W to avoid interfering with large ships. In precautionary area, ships shall navigate with safety speed and maximum speed shall not exceed the speed limit for the sake of safety. Under the premise of no effect to the safety of large ships, small ships in precautionary area may change lane gradually to $\mathrm{M} / \mathrm{W}$, merge with large ship flow, and pass through the reduction section of waterway in turn.

\subsection{Determination of Cell Size and Parameters}

Determination of cell size is usually on the compromise consideration of calculation accuracy and computational complexity by expert judgment [10]. This study takes each cell 
length of $30 \mathrm{~m}$, then waterway length is 1852 cell long; in M/W, ship size $L \in[3,10]$, and velocity $V \in[10,16]$; in $\mathrm{A} / \mathrm{W}$, ship size $L \in[1,4]$, velocity $V \in[2,12]$; Speed limit is 5 cell/ step in precautionary area. Update interval is $60 \mathrm{~s}$, and then run period (1 day) is 1440 steps.

\subsection{Ship Generation Model}

According to on-the-spot observation of ship traffic flow, ship arrival rate obeys Erlang distribution, bow distances between ships follow negative exponential distribution, and ship lengths as well as velocity meet normal distribution.

\subsection{Ship domain and Safety Distance}

Ship domain [11] was first proposed by Fujii Yahei. He proposed that in normal sailing conditions, ship domain is a oval, center thereof is own ship, and long axis/short axis dimensions thereof are $8 \mathrm{~L} / 3.2 \mathrm{~L}$ ( $\mathrm{L}$ is the ship length); when sailing in a harbor or strait, sizes of ship domain decrease to $6 \mathrm{~L} / 1.6 \mathrm{~L}$. However, the definition of Fujii had been considered to be relatively conservative, so the ship domain is too large somewhat. By radar observations, S. M. Liu [12] proposed that ship domain did exist objectively around ships and longitudinal distance thereof was $4.8 L$ with fore and aft ratio about 1.7:1. This study adopts the minimum safety distance between ships as:

$$
\begin{aligned}
& d_{\text {safe1 } 1}=\max \left(3 L_{\text {ownship }}, 1.8 L_{\text {foreship }}\right) \\
& d_{\text {safe2 }}=\max \left(3 L_{\text {ownship }}, 1.8 L_{\text {o,foreship }}\right) \\
& d_{\text {safe3 }}=\max \left(1.8 L_{\text {ownship }}, 3 L_{\text {o,backship }}\right)
\end{aligned}
$$

There $d_{\text {safe1 }}, d_{\text {safe } 2}$ and $d_{\text {safe } 3}$ are safety distance between own ship and fore ship, fore ship and aft ship at neighbor lane, $L_{\text {ownship }}$ is length of own ship, $L_{\text {forssip }}$ is length of fore ship, $L_{\text {o,foreship }}$ is length of fore ship at neighbor lane and $L_{\text {o,backship }}$ is length of aft ship at neighbor lane.

\subsection{Simulation and Discussions}

In this subsection, we would carry out simulation to find out the relationship between transit capacity and bottleneck length, moving speed and ship arrival rate. In the simulation, precautionary area length and ship arrival rate are input parameters, and simulation of each parameter would repeat for 20 times in order to eliminate random effects. In the paper, ship arrival rate is the quantity of arrival ship in 1 minute.

4.4.1. Relationship between Flux and Length of Precautionary Area: Figure 10-12 shows the relationship between flux and precautionary area length under different ship arrival rate in $\mathrm{M} / \mathrm{W}, \mathrm{A} / \mathrm{W}$ and $\mathrm{M} / \mathrm{W}+\mathrm{A} / \mathrm{W}$ (short for "unilateral waterway"). As can be seen from the figures, flux is independent from the length of precautionary area when ship arrival rate is determined. Therefore, the setting of precautionary area length has no obvious affect on flux. 


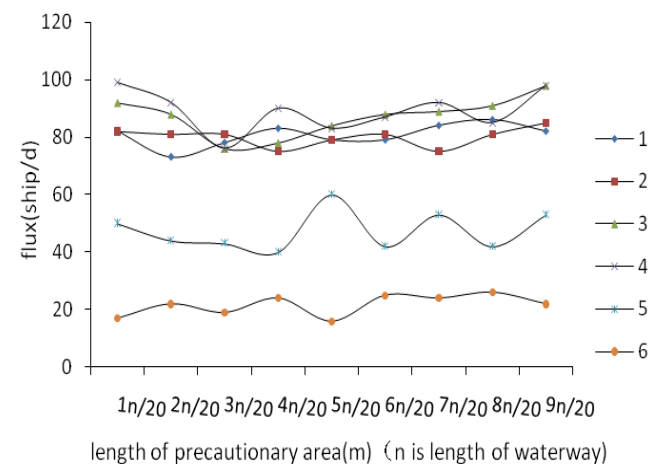

Figure 10. Flux and Length of Precautionary Area in $\mathrm{M} / \mathrm{W}$ as a Function

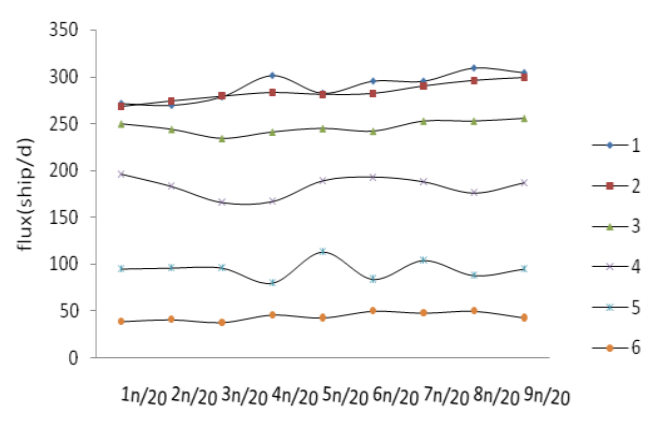

length of precautionary area $(\mathrm{m})$ ( $\mathrm{n}$ is length of waterway)

Figure 12. Flux and Length of Precautionary Area in Unilateral Waterway as a Function

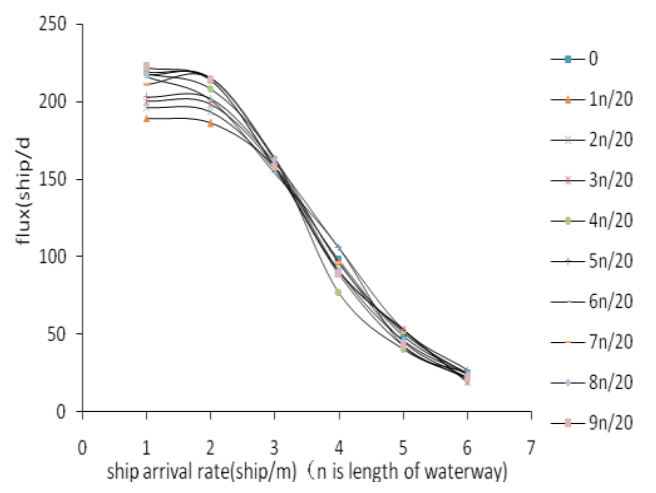

Figure 14. Flux and ship arrival rate in $A / W$ as a function

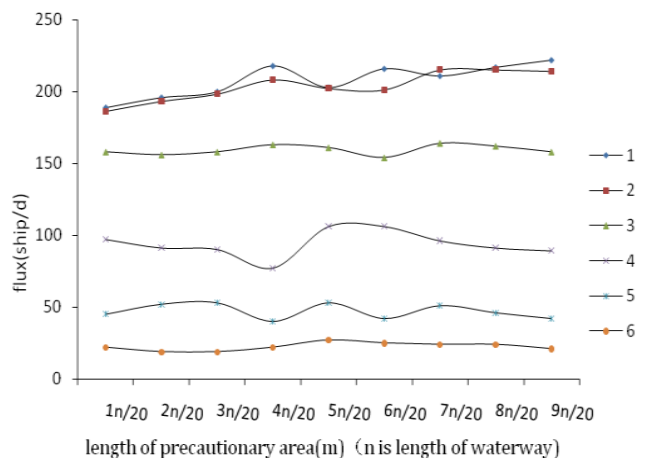

Figure 11. Flux and Length of Precautionary Area in $\mathrm{A} / \mathrm{W}$ as a Function

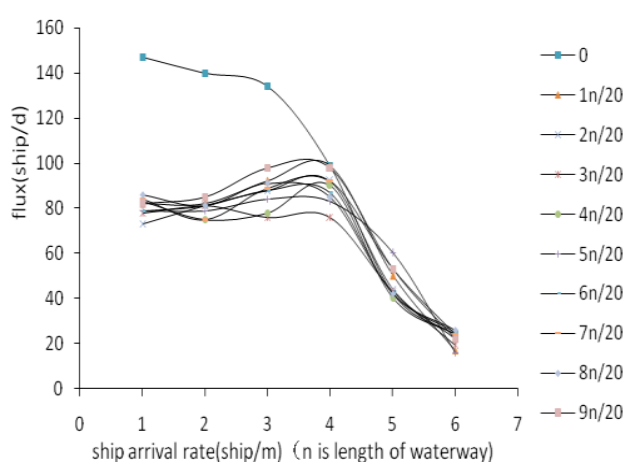

Figure 13. Flux and Ship Arrival Rate in $M / W$ as a Function

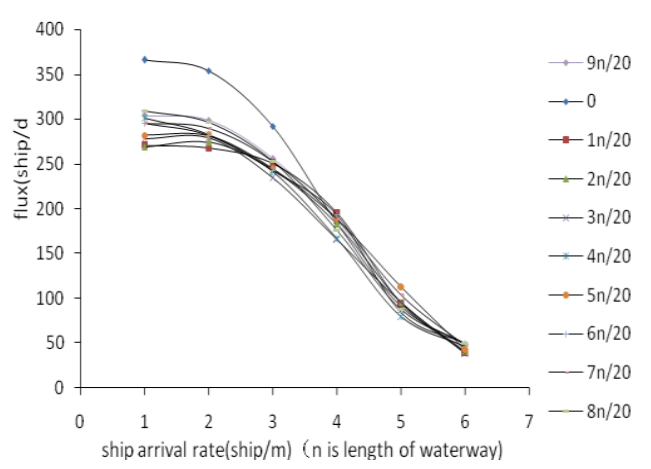

Figure 15. Flux and Ship Arrival Rate in Unilateral Waterway as a Function 
4.4.2. Relationship between Ship Traffic and Ship Arrival Rate: Figures 14-15 show the relationship between ship traffic and ship arrival rate under different precautionary area length in M/W, A/W and unilateral waterway. As can be seen from Figures 14-15, when the length of precautionary area is determined, flux of $\mathrm{A} / \mathrm{W}$ and unilateral waterway monotonically decrease as ship arrival rate increases, wherein the diminishing amplitude and trends of $\mathrm{A} / \mathrm{W}$ are always consistent with that in normal circumstances (length of precautionary area is 0) (as in Figure 14). Therefore, whether A/W closed or not has no effect on ship traffic.

The difference is that, in Figure 13 flux of M/W increases with the increasing of ship arrival rate slowly at first, and reaches a maximum when ship arrived rate is 4 , then decreases monotonically, and the decreasing magnitude and trends are consistent with that in normal circumstances ( length of precautionary area is 0 ). The reason is that with the increase of ship arrival rate, ship density decreases, but speed increases; when ship arrival rate reaches the threshold, ship flux begins to enter a free state, ship density continues to decrease, but ship speed keeps stable, so ship flux reduces.

4.4.3. Effect to M/W Ship Flow by Ship Arrival Rate in A/W: As can be seen from Figure 16 , when ship arrival rate of $\mathrm{M} / \mathrm{W}$ is small (less than 4 ), and if that of $\mathrm{A} / \mathrm{W}$ is less than 4 , ship traffic of M/W is almost not influenced by ships in $\mathrm{A} / \mathrm{W}$; the cause is that traffic flux of $\mathrm{M} / \mathrm{W}$ has stabilized in saturated state. When ship arrival rate in A/W continues to increase, ship flux of $\mathrm{M} / \mathrm{W}$ increases monotonically also, and gradually becomes a free state (ship arrival rate of $\mathrm{A} / \mathrm{W}$ is 0 ).

When ship arrival rate of $\mathrm{M} / \mathrm{W}$ is large (greater than or equal to 4), ship flux of $\mathrm{M} / \mathrm{W}$ is in a free state, at this time, ships of A/W have no effect on M/W almost.

Therefore, when ship density on M/W is high, the transit capacity of large ships in $\mathrm{M} / \mathrm{W}$ can be improved and increased effectively through controlling ship arrival rate of A/W.

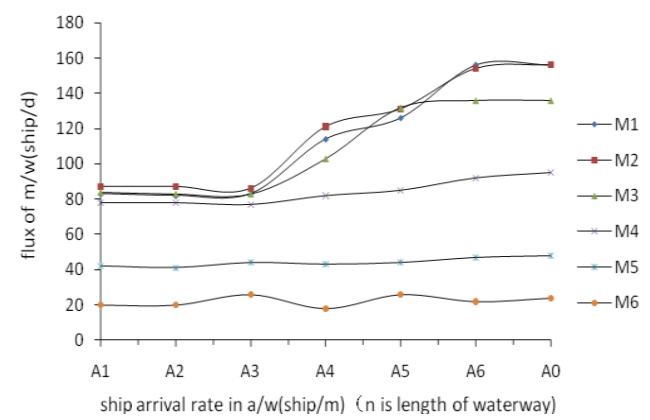

Figure 16. Flux of $M / W$ and Ship Arrival Rate of $A / W$ as a Function

\section{Conclusions}

Through the simulation of ship traffic CA model considering IBS for partial reduction waterway, the paper found:

1) Transit capacity of unilateral waterway was independent from the length of precautionary area.

2) When A/W closed, transit capacity of small ships in A/W was basically not affected. Transit capacity of $\mathrm{M} / \mathrm{W}$ increased first and then decreased as ship arrival rate added; however, there was a critical point existed in the relationship between transit capacity of $\mathrm{M} / \mathrm{W}$ 
and ship arrival rate of $\mathrm{A} / \mathrm{W}$, which can be applied to traffic control of small ships in $\mathrm{A} / \mathrm{W}$ for the purpose of smooth flow in M/W.

Since algorithm is convenient to implement on a computer, and its rules are easy to modify, CA model has a good application prospect in ship traffic research.

\section{References}

[1] D. E. Wolf, "Cellular automata for traffic simulations", Physica A: Statistical Mechanics and its Applications, vol. 263, no. 1, (1999), pp. 438-451.

[2] K. Bentaleb, K. Jetto, H. Ez-Zahraouy and A. Benyoussef, "A cellular automata traffic flow modeling of desired speed variability”, Chinese Physics B, vol. 22, no. 1, (2013), pp. 18902.

[3] Y. Zhou, C. Mi and X. Yang, "The cellular automaton model of microscopic traffic simulation incorporating feedback control of various kinds of drivers", Computer Modeling in Engineering and Sciences, vol. 86, no. 6, (2012), pp. 533-549.

[4] Y. Zheng, Y. Zhang, J. Hu, L. Li and X. Pei, "Simulating coherent flow with cellular automaton model", 2012 15th International IEEE Conference on Intelligent Transportation Systems, Anchorage, AK, United states, (2012) September 16-September 19, pp. 546-551.

[5] J. Vasic and H. J. Ruskin, "A cellular automata-based network model for heterogeneous traffic: Intersections, turns and their connection", 10th International Conference on Cellular Automata for Research and Industry, Santorini Island, Greece, (2012) September 24-September 27, pp. 835-844.

[6] I. Spyropoulou, "Cellular automata model properties: Representation of saturation flow", 10th International Conference on Cellular Automata for Research and Industry, Santorini Island, Greece, (2012) September 24September 27, pp. 817-826.

[7] K. Jetto, H. Ez-Zahraouy and A. Benyoussef, "An investigation of merging and diverging cars on a multilane road using a cellular automation model”, Chinese Physics B, vol. 21, no. 11, (2012), pp. 118901.

[8] F. Yan, M. Y. Pan, D. Q. Wang and X. Gong, "Marine traffic flow simulation based on combination of agent and cellular automata", Journal of Dalian Maritime University, vol. 35, no. 2, (2009), pp. 89-92.

[9] J. X. Liu and F. Zhou, "Simulation of waterway traffic flow at harbor based on the ship behavior and cellular automata", 2010 International Conference on Artificial Intelligence and Computational Intelligence, Sanya, China, (2010) October 23-24, pp. 543-546.

[10] X. B. Qu and Q. Meng, "Development and applications of a simulation model for ships in the Singapore Straits", Expert Systems with Applications, vol. 39, (2012), pp. 8430-8438.

[11] N. Wang, X. Y. Meng, Q. Xu and Z. Wang, "A unified analytical framework for ship domains”, The Journal of Navigation, vol. 62, no. 4, (2009), pp. 643-655.

[12] Z. M. Liu, "The research of the inland waterway transit capacity where ship is crowed", 41, Dalian Maritime University, Dalian, (2006).

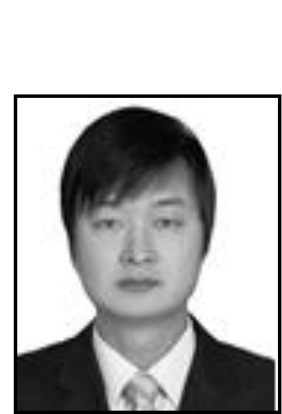

\section{Author}

Hongxiang Feng, he is a $\mathrm{PhD}$ from Shanghai Maritime University major in navigation. $\mathrm{He}$ is also a captain with 12 years of marine experience. His current research interests include marine risk assessment and marine traffic simulation. 
International Journal of $u$ - and e- Service, Science and Technology Vol.6, No.6 (2013) 